\title{
sciendo
}

DOI 10.2478/sbe-2019-0034

SBE no. 14(2) 2019

\section{STUDYING THE USER EXPERIENCE IN ONLINE BANKING SERVICES: AN EYE-TRACKING APPLICATION}

\author{
ȚICHINDELEAN (BECA) MONICA \\ Bucharest University of Economic Studies, Romania \\ CETINĂ IULIANA \\ Bucharest University of Economic Studies, Romania \\ ȚICHINDELEAN MIHAI \\ Lucian Blaga University of Sibiu, Romania
}

\begin{abstract}
:
Neuromarketing as research method contrbutes to understanding consumer behavior a step further than traditional marketing research. The aim of the current study is to explore the usability and cognitive understanding of banking services webpages. In this regard, the theoretical part of the article reviews the relevant literature related to neuromarketing as research method and the use of eyetracker as research technique. Further on, a two-step research design was developed for studying the consumers' attention and memory during and after viewing two Romanian banking services websites. The results showed that the way information is structured and presented on the webpages influence their usabiliy and cognitive understanding.
\end{abstract}

Key words: consumer attention, neuromarketing, eye-tracker, banking services, consumer memory

\section{Introduction}

Given that a regular individual is exposed to thousands of marketing messages on a daily basis, his ability to process information being limited, it becomes more and more challenging for marketing researchers to obtain specific, objective results in consumer research by applying only traditional research techniques.

By combining traditional research methods, such as survey or focus group, with neuromarketing research, one can complete the expressed perceptions of consumers regarding different aspect of the marketing activity with the measured dimensions of their attention, excitement, cognitive or affective response to marketing stimuli. 
When talking about services, the banking services, compared to tourism or other leisure services, can be evaluated as having higher risk, harder to influence by the consumer but also, due to its technicality, harder to understand. Given that the biggest part of the population uses banking services, the websites of the providers - one of the communication means - has to be user-friendly, easy to understand in terms of transmitted information and easy to follow. It is not seldom that consumers choose to collaborate with a bank due the ease of communication, payment systems, online or digital accessibility of the bank. In this context, neuromarketing research techniques such as the eye tracking technique, can provide evidence on how consumers view the information presented on the website, can show the comprehension level of the viewed information, can indicate usability issues and can contribute to the improvement of banks' webpages design.

\section{Literature review}

\section{Neuromarketing - an innovative research method}

The objective of both traditional research and neuromarketing research is the same: discovering valuable information about the consumer, his preferences, his perception and desires. While within traditional marketing research subjects are asked questions, observed as they act in a real or artificially- designed shopping environments or become part of simulation or experiment, the valuable marketing information is deduced from their expressed perception, interpreted from their behavior or reaction, neuromarketing research does not study the consumer, but the consumer's brain and its direct, unaltered reactions to marketing stimuli. Many barriers can stand in front of a truthful expression of perception; either the consumers does not feel comfortable to share his opinion, he does not know how to express it, feels pressured by something or someone to declare a false perception or simply is not capable to fully understand and evaluate his opinion regarding a specific matter. The reaction to a marketing stimulus can be explained in 100 different ways by 100 respondents, put in different words and indicate different results, but by analyzing 50 brains reacting to a stimulus and you may record the same, unaltered answer to the stimulus. People are subjective in analyzing the reaction of their body and brain, but neuromarketing techniques are not (Brenninkmeijer, Schneider, Woolgar, 2019).

Starting from neurosciences which study the nervous system in order to understand behavior (Plassmann, Ramsoy and Milosavlejevic, 2012), going to neuroeconmy, which adds to neurosciences the objective to understand consumers' choices, neuromarketing, viewed as an interdisciplinary science, seeks to influence these decisions by working with psychological constructs such as attention, perception or memory (Breiter et.al, 2015).

Levallois, Smidts and Wouters (2019) present a history of neuromarketing since 2002, when the term was first used in the announcement of the first neuromarketing research company as well as by prof. Smidts himself, until 2008, when neuromarketing was already used in many marketing research projects. Even if 2002 can be considered as the birth year of neuromarketing as a science, previous applications of medical technology in the study of the consumer indicate that the basis of this science existed way before: in 
1979 the pupil dilation of subjects watching advertisements has been measured (Arch, 1979), in the 80s the EEG was used to test the electrical changes in the brain of consumers while watching commercials, while in the 90s Positron Emission Tomography was used at Harvard to study the reaction of consumers to shopping environments.

Nowadays neuromarketing research can be applied through a wide series of instruments and technology. Bitbrain, a brain technology company activating in 35 countries, classifies neuromarketing research techniques in three main categories: (1) register brain physiological activity, (2) register other physiological activity and (3) register behavior and conduct. Zuravicki (2010), Kenning \&Plassmann (2005) and Calvert \& Thensen (2004) propose a similar classification having the first two categories as metabolic brain recording and electrical brain recording.

Following Bitbrain's classification, there are three neuromarketing techniques that can indicate certain changes in the mind and body of the consumer due to marketing stimuli:

(1) Neural activity in the brain: Electroencephalogram (EEG), Magnetoencephalogram (MEG), Functional Magnetic Resonance Imaging (fMRI), Positron Emission Tomography (PET);

(2) Neural activity in the peripheral nervous system: Electrocardiogram, Galvanometer, Facial Coding;

(3) Other techniques: Eye Tracking, Implicit Response Test, Indoor positioning techniques (bitbrain.com)

\section{The Eye Tracker}

The optic nerve transmits the information from the external environment directly to the reptilian brain, the oldest and most impulsive layer of the brain, the visual information being processed first (Peruzzo, 2013). The eye tracker is the instrument that allows researchers to record the eye movement of the subject while he or she is looking at an advertisement, either static or dynamic, thus being able to identify the attractors of the marketing communication and therefore increase its impact. Several studies (Pieters et.al., 1999; Zurawicki, 2010; Plassman et.al, 2012) showed that the eye movement while viewing an advertisement composes of fixations and saccades, respectively moments when the eye is fixating on a certain element, and paths that the eye follows while moving from one fixation to another. The analysis of these scan paths can indicate the attractiveness of each element composing a visual marketing tool. Also, by correlating the results recorded by the eye tracker (scan paths, heat maps, area of interest etc.) with the survey as traditional research method, certain fixations can be explained by the subject in terms of attractiveness.

Aga Bojko's book "Eye Tracking the User Experience: A Practical Guide to Research" (2013) facilitates a top-to-bottom description of the eye tracker as an instrument and as a neuromarketing technique, clarifying aspects from the movement of the eye until the analysis of the data obtained from the eye tracker. Even if in 1947 eye trackers were first used to study the eye movement of pilots while looking at control board of the plane, it was not until the 90s when this technique started being used in marketing field. Eye tracking devices, no matter if fixed (mounted on a computer) or mobile (glasses), work with 
infrared light that is transmitted and then reflected by the retina and cornea. The video camera installed in the eye tracker that records the reflection of the infrared light correlates the position of the eye with the material that is viewed and can therefore establish what the subject is viewing in each exact moment.

The eye tracker records the foveal vision, respectively the area in the center of the eye, but not the peripheral vision. Sometimes information can be received from the peripheral vision- the subject knows information that was not recorded as being seen, other times information that is recorded as being viewed cannot be remembered by the subject as the eye might have landed on a specific information without comprehending it, this being one downside of using the eye tracker.

Being able to show where, for how long, in which order the subject views certain information from a visual marketing stimulus, eye tracking research can offer supporting information for different types of marketing decision. The eye tracker can offer information (qualitative) to improve the design of marketing stimuli by identifying and explaining usability issues and can measure (quantitative) attraction and performance of certain elements.

F.Munoz-Leiva et all (2019) studied a hotel's online advertising (banner displayed on the hotel's social network profile - Facebook, blog, and virtual community profile TripAdvisor) as marketing stimuli and its impact on the customer's visual attention and selfreported memory. The research design is similar to the one proposed in the present article, both objective (eye-tracker) and subjective (self-administrated questionnaire) measurement of the studied variables - visual attention, perception and recall being performed. Empirical data showed that visual attention differed by the used online promotion tool (highest visual attention was obtained for the hotel's Facebook banner) and, that the measured objective data (eye-tracker) differed from the measured subjective one (questionnaire).

Advertising effectiveness within a website was also studied by M.Hernandez et all (2017) in a two-groups eye-tracker experiment. The two groups' subjects differ in accordance with their ability to read only from left to right (LTR) or in both directions (RTL/LTR). The results confirmed the authors' hypotheses that LTR users have a lesser spatial attention than the RTL/LTR users, and that feature-based attention of LTR websurfers is higher than the RTL/LTR ones.

Pan et all (2004) used the eye-tracker device to understand the web page viewing behavior through its determinants. In their study, eye-tracker specific data was modelled alongside with questionnaire-based data for finding differences and/or similarities which could explain the webpage viewing behavior. Their article's findings suggest that webpage viewing behavior is driven both by demographical aspects of the viewer (gender), and by stimuli characteristics (order of the pages viewed and interaction between websites' type and order of the pages viewed).

\section{Methodology}

Preliminary phase of the research: As a result of previous research aimed at analyzing the marketing communication in the banking field and the way marketing 
specialists consider useful the application of neuromarketing research, we can conclude that one of the most used and efficient channels of communication used by banks is their own website. Last but not least, banking marketers presented the information they would like to learn about consumer behavior by applying neuromarketing research techniques. Given that the most frequent answer referred to the way consumers view the information when they visit the website of the bank, this research seeks to identify the expressed and implicit perception (as measured by the eye tracker) of banking websites visitors. The two studied variables, expressed and implicit perception, are measurements of consumers' memory and attention, both essential constructs of consumers' cognitive understanding process.

After analyzing the data, we should be able to achieve the current research's purpose of identifying the features of the landing page elements that help increase its ease of use. Derived from the research purpose, the research purpose is defined: identify the relationship between the elements that were memorized after viewing the bank websites (memory) and the attractor items recorded by the eye tracker in the heat map (attention).

Projection phase of the research: The present study is based on primary information collected through survey (questionnaire) and neuromarketing (eye tracking) methods. The provided information free of charge and respondents were selected randomly, although an equal distribution based on gender and level of education has been desired. Effective data collection was conducted through direct field research during 25.03.2019 -01.04.2019.

Given that this research uses a neuromarketing technique, the used sample size was not determined by calculation, thus not being statistically representative. The number of respondents was 22 people aged 21-36, of whom 12 female and 12 male. Most respondents (45.5\%) are Master graduates, $27.73 \%$ Bachelor graduates, $22.73 \%$ high school graduates and only $4.55 \%$ attended doctoral studies.

The implementation phase of the research: Following an informative session regarding the experimental procedure, each subject gave his consent to participate in the study by signing a consent form. Subsequently, each subject filled out a physical questionnaire with questions about their own consumption behavior of banking services. After completing the questionnaire, the subjects were seated in front of the laptop on which the eye tracker was mounted; the device has been calibrated for each subject individually so that their gaze is recorded as accurately as possible throughout the study.

Each of the home pages of the websites of five selected banks was presented to the subjects as marketing stimuli. For each of the images, the subjects had 4 distinct tasks to go through: (1) identifying the location where they can find out more about the bank's exchange rate, (2) identifying the location from where they can find the shopping card information, (3) identifying the location where they can find information about the mobile banking application and (4) free viewing of each image for 1 minute. Following each of the first three tasks, the subjects assessed the ease of identifying the requested information on the page. Following the fourth task, the subjects responded to a detailed questionnaire in which they presented the items that stood out and which they memorized on the visualized web page, evaluated the different features of the web page and expressed their willingness 
to collaborate with each of the banks. After each task was fully covered for each of the five images of the bank's website, only then the subject went to the next task.

The data obtained by applying the questionnaire and using the eye tracker were encoded and processed by creating a database in the IBM SPSS statistical analysis program, version 22. The present paper presents the results obtained after the 1 minute free viewing of the home page of two banking websites.

\section{Empirical findings}

Following a 1-minute free viewing of the main page of the website of each of the banks surveyed, the respondents were asked to mention the items that stood out and which they memorized regarding the layout and content of the home pages. During the minute they viewed each web page, the eye tracker recorded the subject's gaze, the results being encoded in a heat map showing which elements received the most attention. In the following part we will correlated the list of memorized elements with those highlighted by the heat map, assessing respondents' cognition regarding the visualized elements.

A. Banca Transilvania

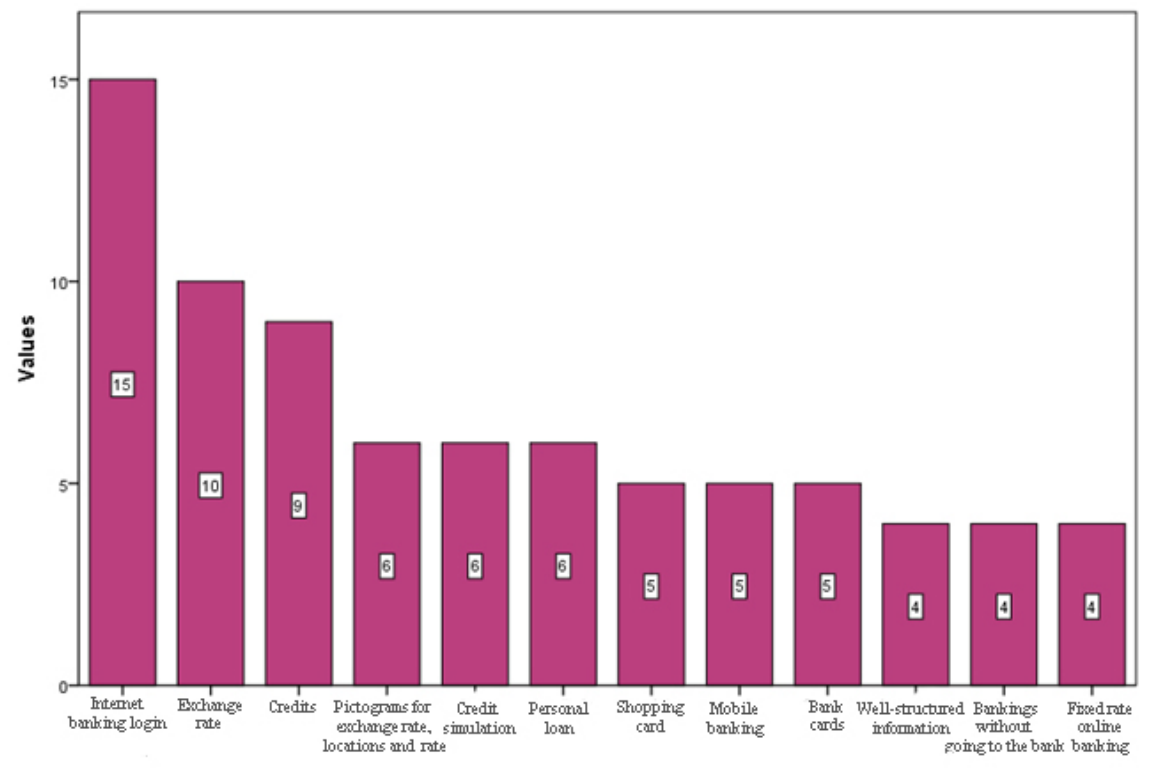

Graphic 1: Memorized elements - Banca Transilvania (I) 

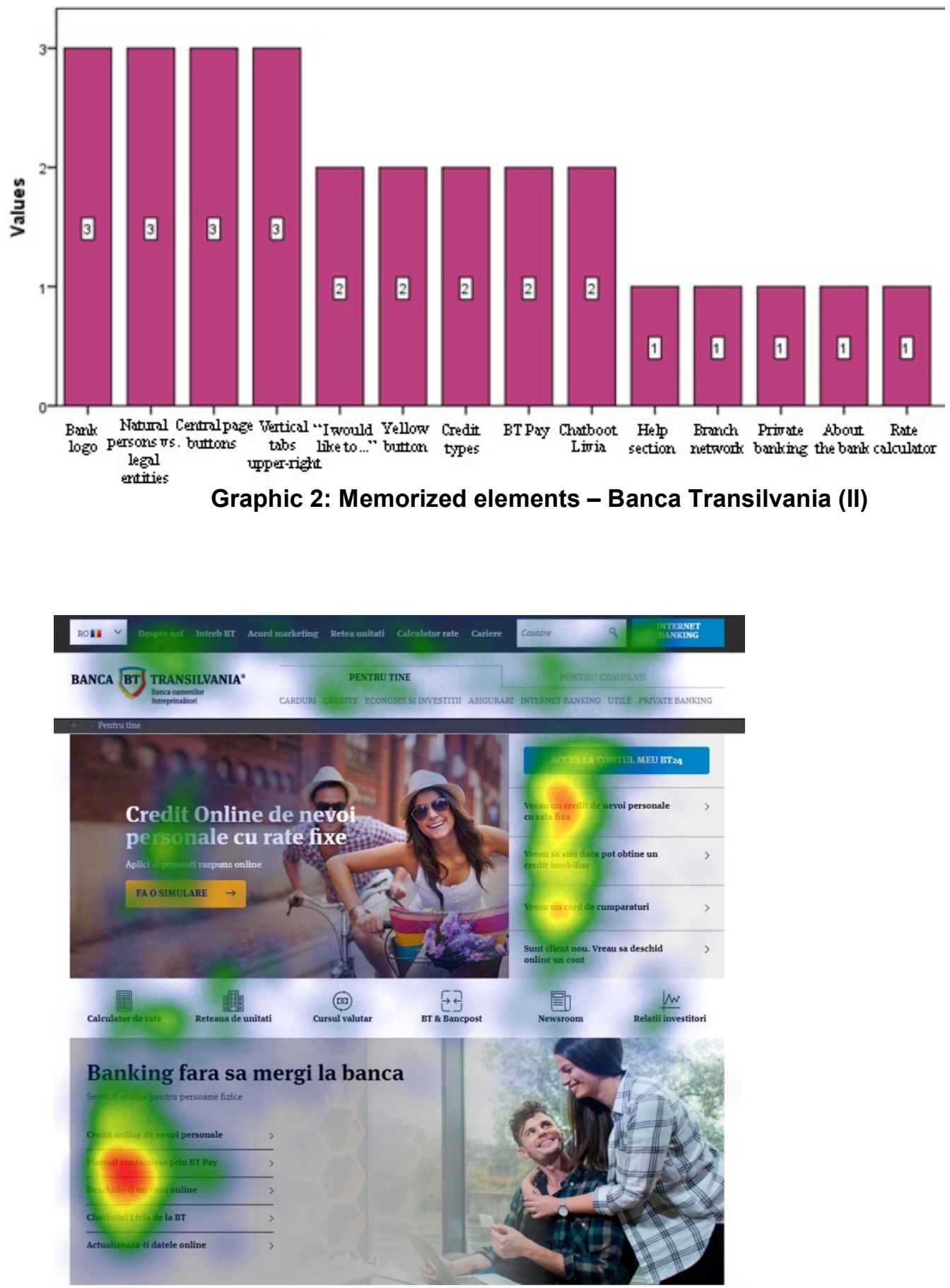

Picture1. Heat map of the visualized elements on Banca Transilvania home page

By analyzing the answers of the subjects regarding the highlighted and memorized items from the home page of Banca Transilvania's website, we notice that most people have remembered the login button for the internet banking account. The eye tracking 
analysis shows that this item has been viewed, but not for a long time, this information being only fast scanned. We can justify the frequency of this mention by the fact that the subjects had to identify the Internet Banking section within the third task, so the information was already retained from previous views. The same situation occurs in the case of the exchange rate, the second most frequent response, which was the subject of the first task performed by the subjects. The following answers, respectively credits and icons in the center of the page are confirmed by the heat map as having an average view rate.

According to the heat map, the most frequently viewed elements on the main page of Banca Transilvania website were as follows, the frequency of their expression in the questionnaire being parenthetically indicated:

- I want a fixed rate personal loan (6 respondents)

- I want a shopping card (5 respondents)

- Banking section without going to the bank and the component sub-sections (4 respondents):

○ a personal need credit (6 respondents)

- Livia chatbot (2 respondents)

- update your online data

- $\quad$ Make a simulation (6 respondents)

By defining Areas of Interest (AOI) in the analysis software of the eye tracker, statistics on each selected elements can be analyzed for each studied image. We can therefore find out the viewing sequence for each element, the mean fixation duration or if the subjects revisited the same element after viewing it the first time. The following picture shows the result of the $\mathrm{AOI}$ analysis, further analysis being performed in a short form.

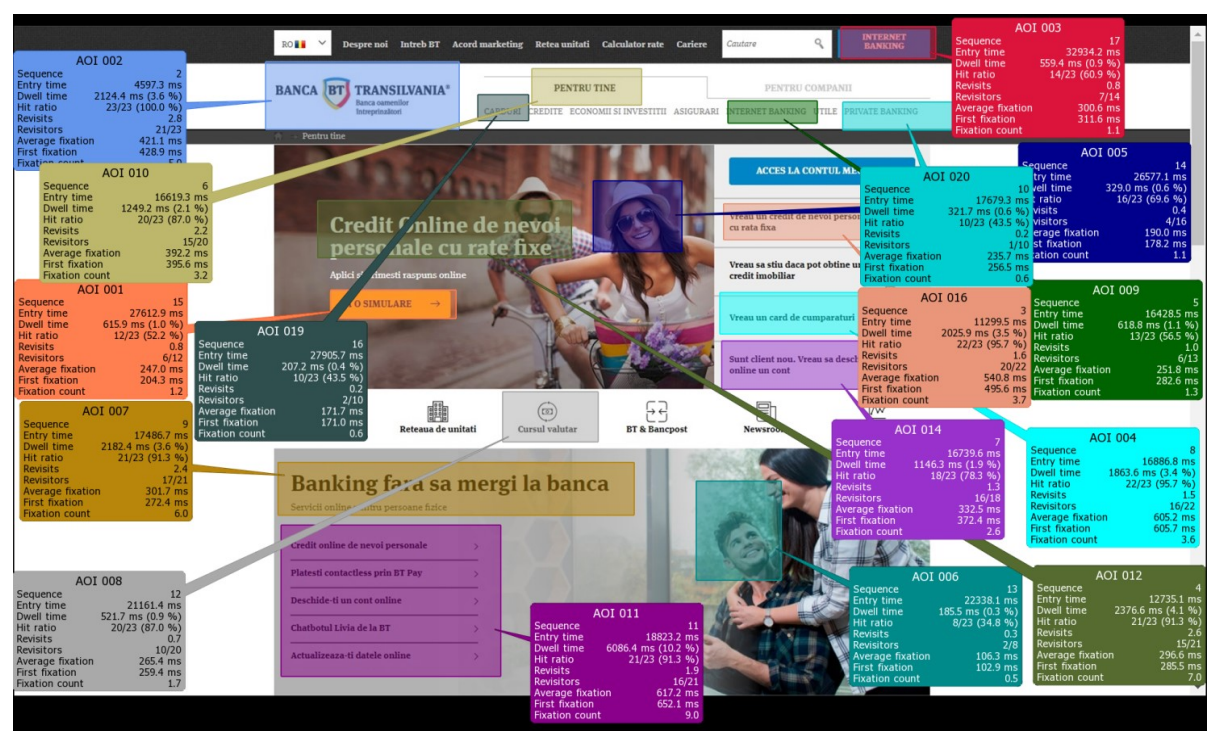

Picture 2: Areas of interest in analyzing the results obtained through the eye tracker 
Table1. Eye tracker information on the most frequent mentioned items (BT)

\begin{tabular}{|c|c|c|c|c|c|}
\hline Memorized element & 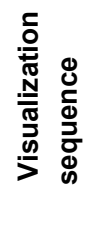 & 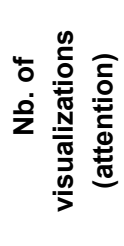 & 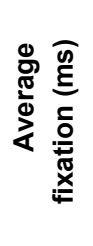 & 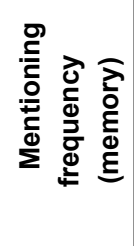 & 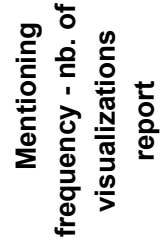 \\
\hline Login Internet Banking & 17 & 13 & 300 & 15 & 1.15 \\
\hline Exchange rate & 12 & 20 & 265 & 10 & 0.50 \\
\hline Credits and loans & 9 & 7 & 210 & 9 & 1.29 \\
\hline Exchange rate icon & 12 & 20 & 265 & 6 & 0.30 \\
\hline Credit simulation picture & 15 & 12 & 247 & 6 & 0.50 \\
\hline Personal needs loan & 3 & 22 & 540 & 6 & 0.27 \\
\hline Shopping card picture & 1 & 5 & 43.9 & 5 & 1.00 \\
\hline Bank cards & 16 & 10 & 171 & 5 & 0.50 \\
\hline Banking without going to the bank & 9 & 21 & 301 & 4 & 0.19 \\
\hline Online fixed rate credits & 4 & 21 & 296 & 4 & 0.19 \\
\hline
\end{tabular}

By comparing the most frequent mentioned elements with the recorded frequency of the same elements, we can conclude that:

- Internet Banking was the most memorized element of the page. Although $60 \%$ of respondents viewed this item, its average viewing time was only $300 \mathrm{~ms}$. We believe that this information was memorized in previous tasks. The same situation occurs with the Exchange Rate, where the viewing time was $265 \mathrm{~ms}$. and $50 \%$ of respondents recalled this element.

- $\quad$ Among the most viewed information, the "personal needs loan" section, mention by 6 respondents, is found both as an individualized information (viewed by $95.7 \%$ of respondents, with an average viewing time of $540 \mathrm{~ms}$.) and part of the "Banking without going to bank" section (viewed by $91.3 \%$ respondents, with an average viewing time of 617 $\mathrm{ms}$.). In the list of the most frequently mentioned items, this is also the first observed item, being the $3^{\text {rd }}$ element viewed after accessing the website.

- $\quad$ The "I want a shopping card" element was mentioned by 5 respondents even if it was viewed by $95.7 \%$ of respondents, averaging $605.2 \mathrm{~ms}$ viewing.

- $\quad$ Some respondents, although they viewed some sections, did not memorize the exact information, naming only general features such as the button color, section structure, or the existence of an image.

- Taking into account the ratio between the mentioning frequency of an element (memory) and the number of views recorded by the eye tracker (attention), we can say that the best performing element was the credit simulation picture, having an average viewing time of $247 \mathrm{~ms}$. 50\% of those who saw this item have also memorized it and mentioned it after the viewing time.

Moreover, both the heat map and the scan paths of the page's indicate that the user's view will navigate horizontally, on lines or vertically, on columns and not in a random, chaotic pattern. Therefore, the information presented on a bank website should 
be structured on lines and columns so that the consumer's eyesight can naturally go through all the information.

If we are to arrange the mentioning frequency of the memorized items and the number each item was visualized by the sample and compare them against the main diagonal of the graph, the following situation is obtained for Banca Transilvania.

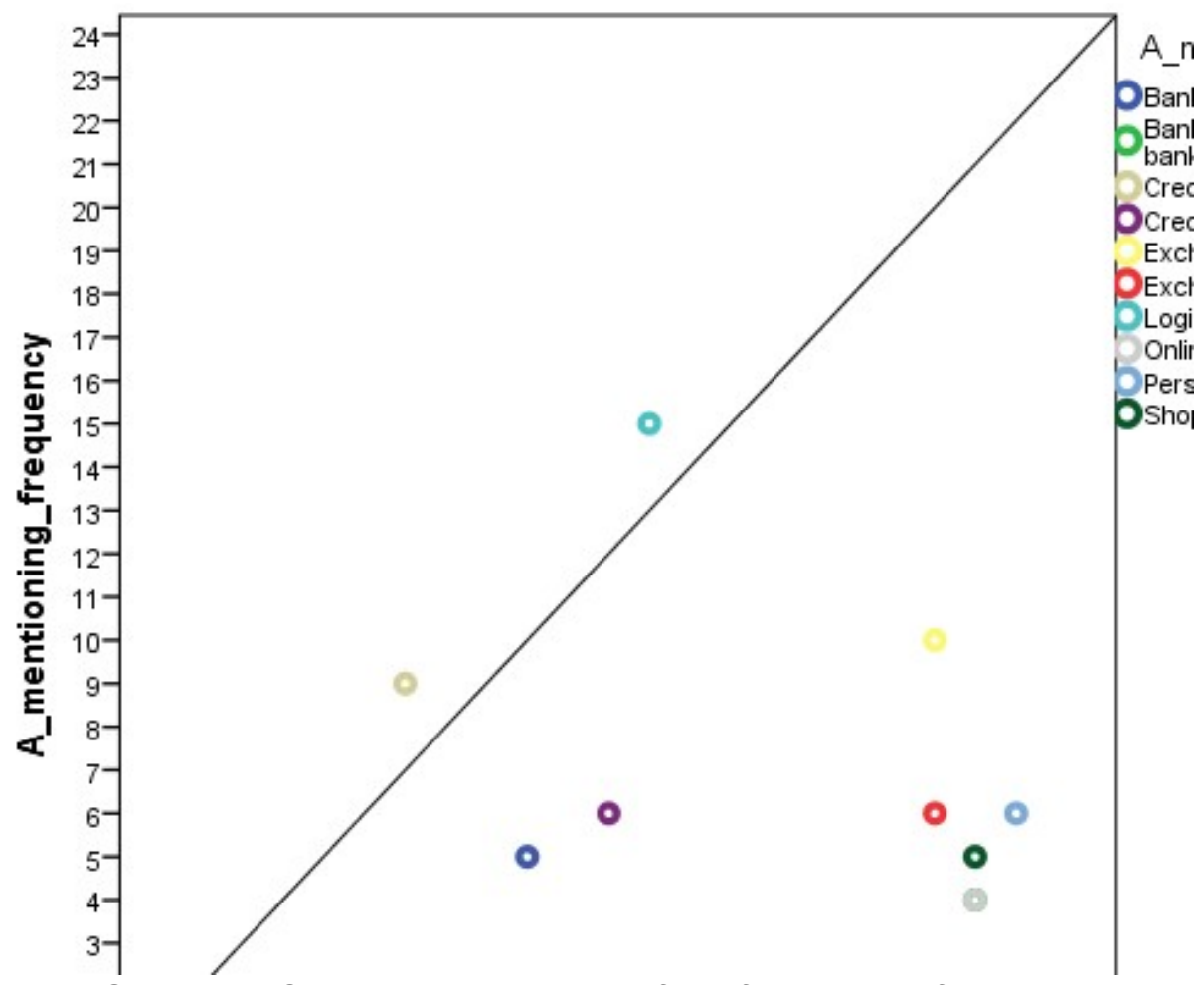

Graphic 3. Scattered dots graph of the frequency of memorized elements (memory) vs. number of visualization of each of them (attention) (Banca Transilvania)

The best performing elements, the closest to the diagonal in the lower side, are the "banking cards", the "credit simulation picture" which is centered in the upper part of the page and "exchange rate", also positioned in the middle of the screen.

The two elements above the diagonal, "credits and loans" and "login internet banking" represent cases where the mentioning frequency was higher than the actual visualizing count. Given that "internet banking" was the subject of the second task performed by the subject and that "credits and loans" is general information that can be found on any webpage of a bank, we consider that these elements were mentioned based on past memory and experience and not as a result of viewing them specifically. 

B. BRD

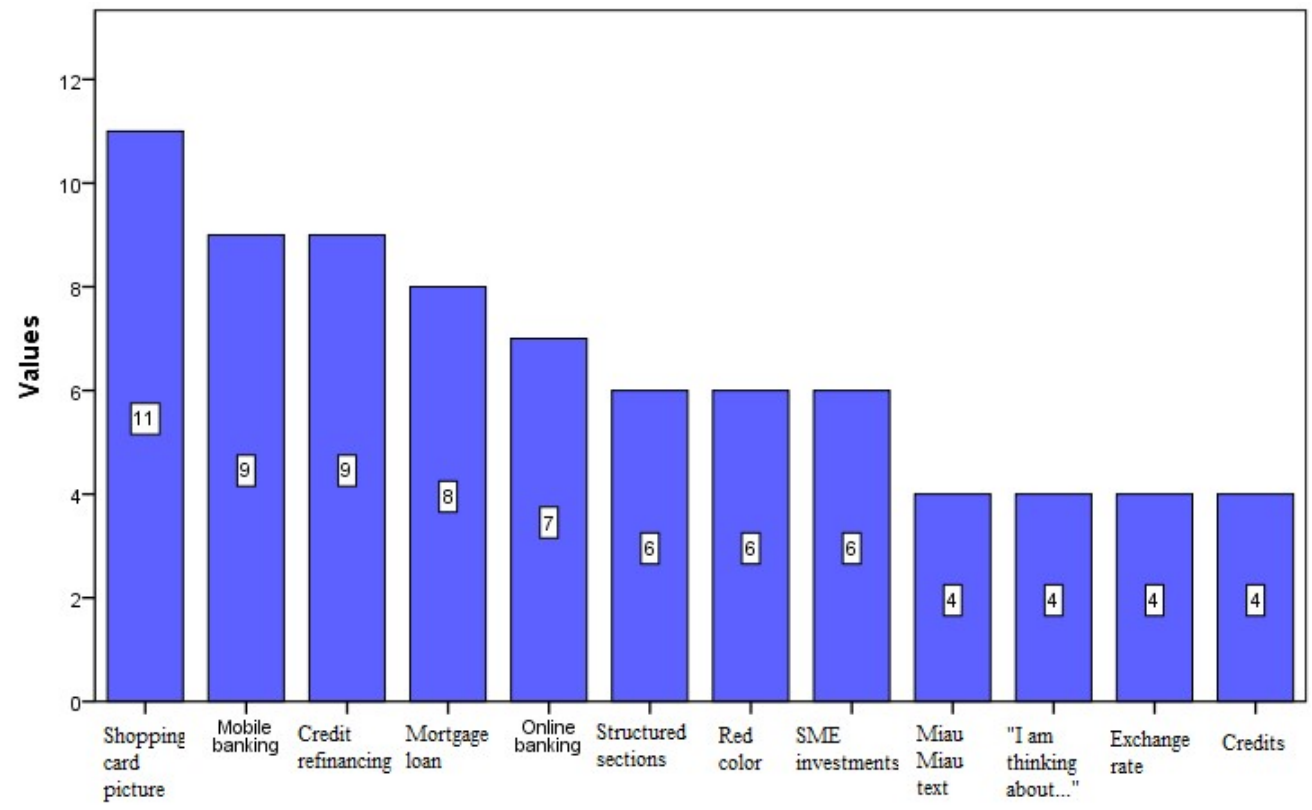

Graphic 4: Memorized elements - BRD (I)

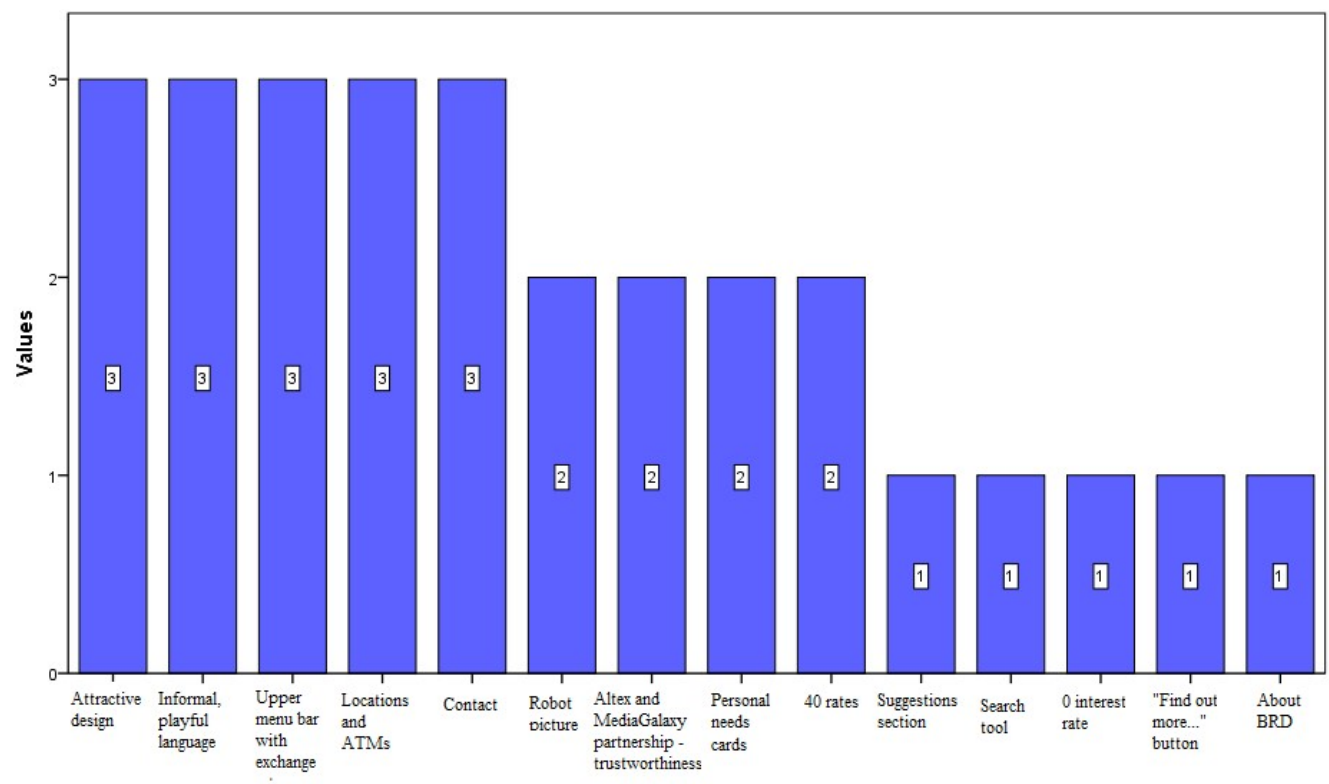

Graphic 5: Memorized elements - BRD (II) 


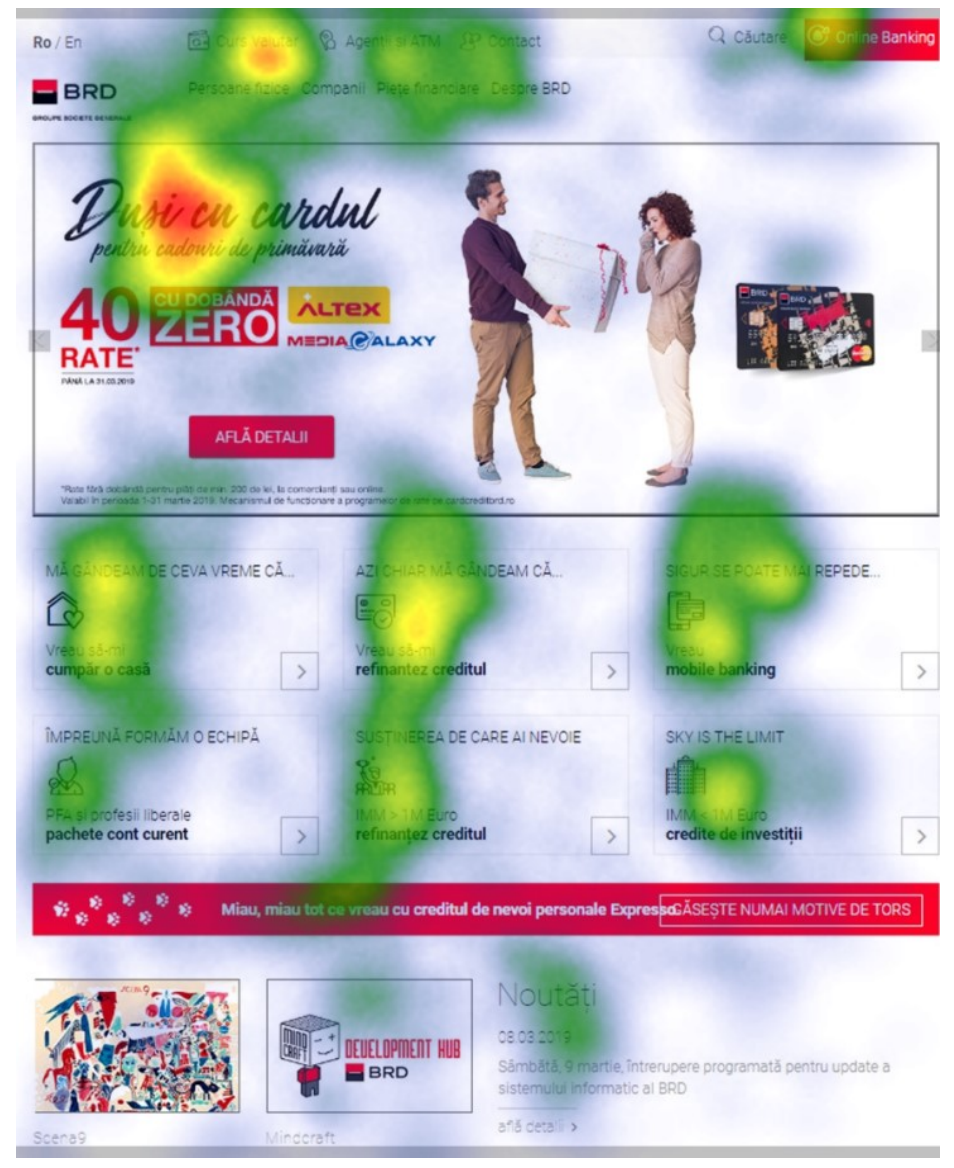

Picture 3. Heat Map BRD in free viewing conditions

Table 2: Eye tracker information on the most frequent mentioned items (BRD)

\begin{tabular}{|c|c|c|c|c|c|}
\hline Memorized element & 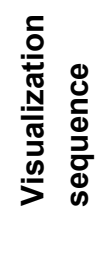 & 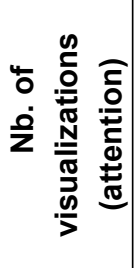 & 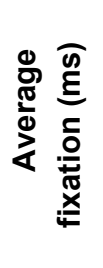 & 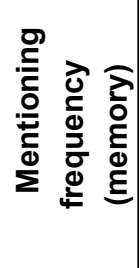 & 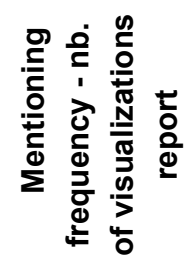 \\
\hline Shopping card picture & 1 & 21 & 413 & 11 & 0.52 \\
\hline Mobile banking & 7 & 19 & 597 & 9 & 0.47 \\
\hline Credit refinancing & 4 & 20 & 437 & 9 & 0.45 \\
\hline Mortgage loan & 6 & 14 & 400 & 8 & 0.57 \\
\hline Online banking & 19 & 12 & 410 & 7 & 0.58 \\
\hline SME Investments & 14 & 20 & 391 & 6 & 0.30 \\
\hline Miau Miau - red line & 9 & 19 & 328 & 4 & 0.21 \\
\hline Exchange Rate & 5 & 16 & 430 & 4 & 0.25 \\
\hline
\end{tabular}


By analyzing the subjects' responses in parallel with the eye tracker's attention recording of the elements of the homepage of the BRD website, we notice that the promotional banner of the shopping card is the one that drew the greatest attention. Thus, the shopping card image was the most common answer (10 out of 22 respondents), the title "Gone with the card" in this image being the most viewed section and the first item seen after the page was accessed by the subjects. We can see, therefore, that although the memorized item refers to the entire image of the promotional offer, the visual focus was on the title, written with a different font from the other sections and with a larger size.

In the list of subjects' responses, we find other information that has been retained on this picture: the partnership with Altex and Media Galaxy that makes the bank trustworthy (2 respondents), "40 rates" (2 respondents), "0 interest" (2 respondents). We notice that the first and longest viewed element $(423 \mathrm{~ms})$ is the title "Gone with the card", followed by visual section "40 rates- 0 interest - Altex, Media Galaxy". The picture of the card and that of the people did not attract attention to the same extent, being observed much later and only for a short moment.

From the heat map analysis, we notice that the most viewed areas are the currency exchange rate and the refinancing section of the loan. 9 respondents mentioned credit refinancing as a memorable item, the exchange rate being mentioned only 4 times, probably due to the fact that this item was the subject of a previous task and was therefore not considered unique. The mobile banking section, also seen in a previous task, has been mentioned 9 times, the attention coverage of this section being wider, subjects reading the title and text of the ad.

Given that the information on the BRD homepage is structured in successive batch format, we observe from the heat map that the subjects viewed each of the 6 successive sections, obtaining a vertical viewing template. Of the six sections, the first three, placed on the horizontal line, were those viewed and memorized to a greater extent.

We also notice that the online banking button has been viewed and memorized, this item being mentioned by 7 people. We consider the use of red color to help highlight this element, 6 respondents mentioning the use of this color as being effective. The information on the ratio between the frequency of the mention and the number of views indicates that this item had the best performance, $58 \%$ of those who viewed this item memorizing it.

In addition to the above-mentioned items and information, we also notice that some design or layout aspects have been pointed out. Thus, the following elements attracted the subject's attention, being expressed within the survey part of the research: the structure by categories and borders, the use of the red color, the wording "I want to ... I I think ...", the informal, playful form of expression, the structure and composition of the main menu bar. 


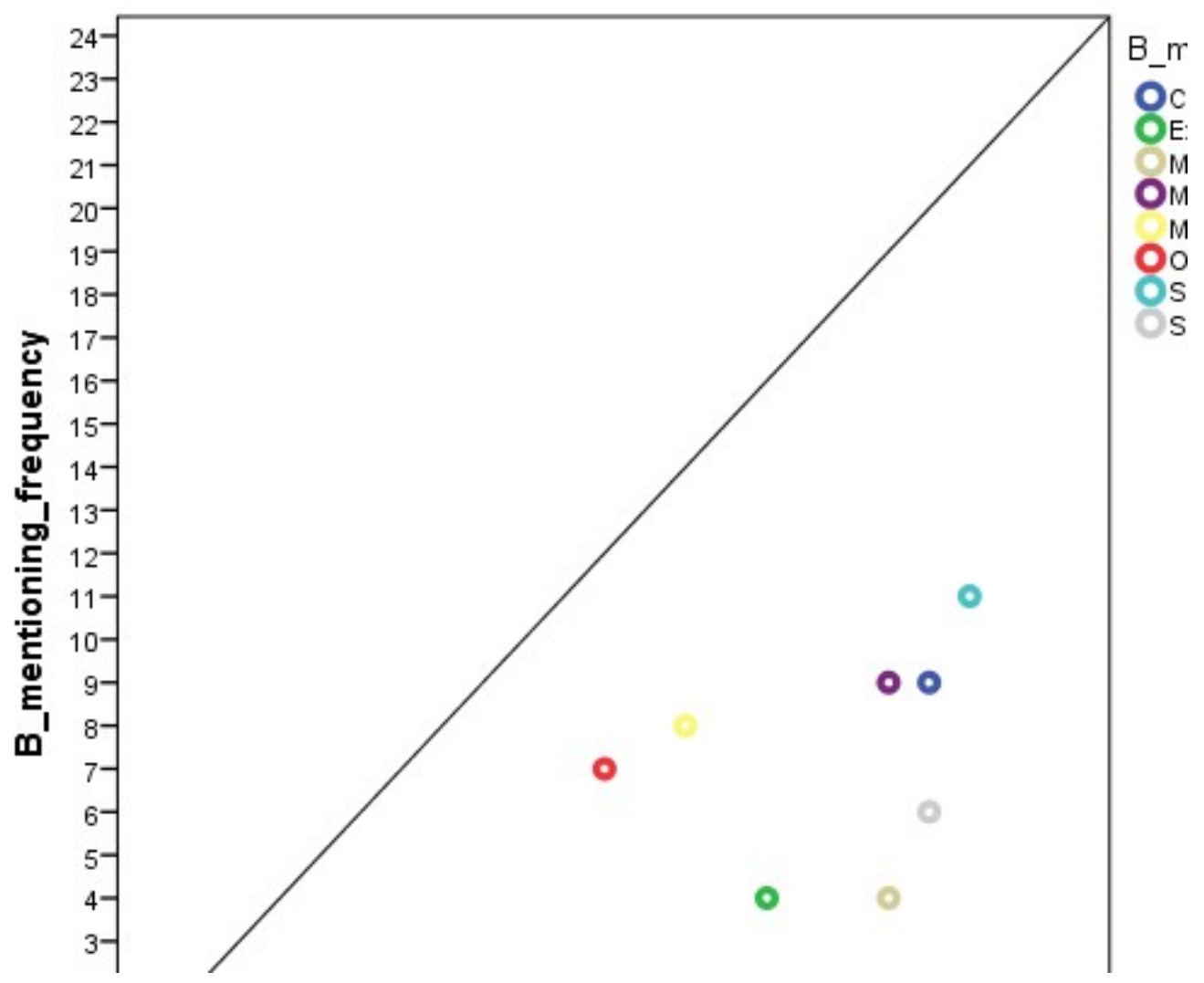

Graphic 6. Scattered dots graph of the frequency of memorized elements (memory) vs. number of visualization of each of them (attention) (BRD)

Compared to the scattered dot analysis for Banca Transilvania, we can see that in the case of BRD all the values are below the main diagonal of the graph, meaning that all the viewed elements had a lower mentioning count compared to the number of times they have been viewed. The elements positioned closest to the diagonal and therefore the best performing in terms of memory are "online banking" which is highlighted by the red color, "mortgage loan" which is positioned first in the 6-box information series and "shopping card picture" which is big and central in the upper side of the page.

\section{Conclusion}

By analyzing the results recorded by the eye tracker (attention) combined with the responses of the subjects regarding the elements they memorized after viewing the landing pages (memory) of the websites of Banca Transilvania and BRD, more conclusions about the way consumers view, pay attention and retain information on a banking website page can be drawn.

- In the circumstances that subjects interacted with the webpage before, their past experience and memory influence their recall of information during the task. One alternative is that the elements memorized before have a higher mentioning rate, even if 
these have not been intensively viewed, the other one being a lower mentioning rate due to the redundancy of discussing elements that have been previously in the spotlight. In the future, the frequency of using and accessing different types of online banking services by the customers will be added to the study, so that the accuracy of memory evaluation within a certain task will be higher.

- $\quad$ Given that the pictures (promotional banners) posted on the upper side of the page were in both cases one of the best performing element in terms of retention, we can conclude that information transmitted through pictures, in a visual form, need a shorter viewing time in order to be retained. Even if different subjects mentioned different specific elements of the content of the picture, most frequently the picture itself and the title or main subject is being remembered.

- Bright and outstanding colors catch the eye and increase the chances of information being remembered. We could see this aspect mentioned specifically or deduced by analyzing the color used to present retained information.

- The use of different fonts and text sized increase the attention of the user and the chance of that information to be retained

- Consumers' viewing patter will usually respect a vertical and horizontal path, following the defined sections and tabs. In the case of BRD, where 6 separate, box-shaped sections are used to present the information, attention falls on the first three presented in the first line, with the first one being highly memorized. This finding indicates that information on a banking website should be presented in a structured way, too much text or too many sections and subsections implying a risk for the consumer not to browse the whole information.

- By analyzing the position in the page of the memorized elements, we can conclude that essential information should be placed in the center and upper part of the webpage.

- Comparing the memory efficiency in the case of Banca Transilvania and BRD, we can see that a lower retention of information was obtained for BRD. This result can be justified by the way the information was structured, respectively in a more dull way, in boxes with 3 lines of text compared with Banca Transilvania where most of the information is presented through a picture or a colorful background and through the use of a bullet list.

\section{References}

Arch, D. C. (1979). Pupil dilation measures in consumer research: applications and limitations., Advances in Consumer Research, 6(1), 166-168;

Bojko, A., (2013), Eye Tracking the User Experience: A Practical Guide to Research, Rosenfeld Media; 1st edition;

Breiter et al., (2015), Redefining neuromarketing as an integrated science of influence, Frontiers in Human Neuroscience ;

Brenninkmeijer, J., Schneider, T., Woolgar, S., (2019), Witness and Silence in Neuromarketing: Managing the Gap between Science and Its Application, Science, Technology, \& Human Values $X X(X), 1-25$;

Calvert, G.A. \& Thensen, T., (2004) Multisensory integration: methodological approaches and emerging principles in the human brain, Journal of Psychology, 98; 
Hernández, M.D., Wang, Y., Sheng, H., Kalliny, M., Minor, M. - Escaping the corner of death? An eye-tracking study of reading direction influence on attention and memory, Journal of Consumer Marketing, Vol. 34 (1), p.1-10

Kenning, P. \& Plassmann, H., (2005), NeuroEconomics: An Overview from an Economic Perspective. Brain Research Bulletin, 67, 343-354;

Levallois,C., Smidts, A., \& Wouters, P., (2019), The emergence of neuromarketing investigated through online public communications (2002-2008), Business History;

Munoz-Leiva, F., Hernandez-Mendez, J., Gomez-Carmona, D. (2019) - Measuring advertising effectiveness in Travel 2.0 websites through eye-tracking technology - Physiology \& Behavior, Vol.200, p. $83-95$;

Pan, B., Granka, L.A., Hembrooke, H.A., Feusner, M.,K., Gay, G.K., Newman, J.K., (2004) - The Determinants of Web Page Viewing Behavior: An Eye-Tracking Study in Proceedings of Eye-Tracking Research \& Application Symposium (ETRA 04), ACM, New York, p. 147 - 154

Peruzzo, M., (2013), The three minds of neuromarketing, Curitiba Ipdois Neurobusiness;

Pieters et al., (1999), Visual attention to repeated print advertising: A Test of Scanpath Theory, Journal of Marketing Research, Vol. 36, No. 4,pp. 424-438;

Plassman H., Ramsřy, T.Z., Milosavljevic, M, (2012), Branding the brain: A critical review and outlook, Journal of Consumer Psychology 18-36

Zurawicki, L., (2010), Neuromarketing, Exploring the Brain of the Consumer, Berlin Heidelberg. Springer-Verlag;

https://www.bitbrain.com/blog/neuromarketing-research-techniques-tools, retrieved 26.06.2019 